snch lesions constituted the proximate cause of the disease. No further steps had been taken to establish the truth of this doetrine, and that therefore had been taken as a matter of assumption which ought to have been made a matter of demonstration. Further, he would observe that the clinical history of the disease and the progress of symptoms did not support this theory. It was quite true that in some cases the first irritations commenced in the region of the femoral vessels, but in others it was far otherwise; in some they commenced in the back, in others in the bip, sometimes in the calf of the leg, and more frequently in the popliteal region. Again, one leg might be affected alone or both concurrently; or the disease, after having attacked one, may pass on to the other, or a superior extremity might be affected; and he had lately met with a case in which, after sfmptoms of the di-ease had successively declared themselves in the left lower and upper extremities, the malady u'timately established itself in the right arm, the whole right upper extremity being hot, swollen, and tense, the surface exquisitely paintul, with loss of motor power, and a tense, corded condition of the basilic vein. Now it appeared to him that these facts were inconsistent with the theory that the proximate cause of the disease was essentillly inflammation of the crural veins. They pointed to the existence of some more general and diffusive cause, in regard to whirh it was probable that phlebitis itself was but a secondary affection. A gain, he would point to the general experience of the profession as being opposed to this theory. It was now upwards of thirty years since it was first promulgated by his friend and teacher, the late Dr. David Davis; and although the facts upon which it rested were well known, it was yet very far from being generdly adopted. Thus in this country Dr. Burns affirmed that the nerves were as much affected as the veins. Others regarded the lymphatic vessels as being principally affected; whilst many, dissatisfied with these restricted views of the pathology of the disease, preferred the theory of the late Dr. Hull, that it consisted in a general inflammation of the several organs and structures of the affected $1 \mathrm{mb}$. So again, on the Continent, the greatest difference of opinion existed respecting its nature and pathology; and whilst many affirmed that it consisted essentially in inflammation of the lymphatics, and others that it was a specific inflammation of the cellular tissue, nearly all agreed that in its general characters it differed widely from ordinary phlebitis. Now this diversity of opinion existed notwithstanding that all were aware of the facts upon which the phlebitic theory of the disease rested, and it afforded a powtrful argument against it, because it tended to show thât when tested hy general experience, and considered irrespectively of particular facts, and trefrom bias. it failed to account rationally for all the $\mathrm{kn}$ »wn phenomena of the disease, and consequently could be regarded as its proximate cause. Then in the stquela of the disease circume stances are met with which are inconsistent with this theory. We know, for instance, that after an attack of the disease, the crural veins were generally left impervious or obliterated, and yet it would happen that successive attacks of the disease might occur in the same extremity. Now if it was true that the first attack left them in the condition described, it was difficult to understand how, having functionally ceased to exist, they could again take on functional activity, and become the seat of active inflammation. So also it happened after an attack of the disease that the limb would be left for many years, or even for the remainder of life, in a weak, sensitive, and irritable condition, being easily affected by atmosphezic and consitutional influences. It was easy to reconcile these facts with the notion that the nerves had been injured or damaged by the attack, but not with the idea that the veins alone had been affected. On all these grounds, then, it appeared to him ( $\mathrm{Dr}$. Mackenzite) that the phlebitic theory of the disease was either defective or erroneous. But assuming for a moment that it was correcl, he would yet observe that it left much which was still to be explained. We had yet to learn the nature of that peculiar inflammation of the veins which was so exceptional and so different trom ordinary phlebitis. Did it de pend upon some peculiar disposition on the part of the venous coats to take on diffusive inflammation, or did it depend priniarily upon the blood? If we adopted the first of these theories, we were bound to state the nature of the peculiarity, and the laws of its derelopment. For to be satisfed with merely giving it a name and to speak of it as a "specifie" inflammation was not to advance our scientific knowledge, but rather to take refuge, or to hide our ignorance under the shadow of a name. If, on the other hand, we accepted the latter view, and regarded the venous inflammation as dependent upon some morbid condition of blood, then, indeed, we might reasonably account not only for the pecu. liarities it presented, but for all the several lesions of other organs, and the structural changes with which it was associated. U pon this view also we might reconcile the conflicting opinions respecting the nature of the disease which had been held by different pathologists, and the variations which it manifested in its symptoms and progress in different cases. But in accepting this view we must forego the theory that phlebitis was the proximate cause of the disease, and regard it, as it really was, as a secondary rather than a primary phenomenon; related to the other lesions of the extremity not so much in the order of cause and effect, but as being, like them, a parallel effect of some more general and diffusive morbific agent.

Dr. LEE in his reply entered into the literary history of the disease under discussion, from the time of Mauriceau to the present. He particularly dwelt upon the facts originally published by the late Dr. Davis, and showed at great length his (Dr. Lee's) own labours in this disease. In answer to Dr. Mayo, he said that there were no antecedent symptoms calling for any treatment. He knew nothing of the comparative frequency of the disease. In respect to the views advanced by Dr. Mackenzie, he could only say that, whilst he (Dr. Lee) admitted that there might be a blood disease present, it was consecutive to the inflammation in the veins. That inflammation was in reality the proximate cause of the disease. The scalpel had shown this; he thought that was sufficient, and could not understand what further was required.

\section{MEDICAL SOCIETY OF LONDON.} Dr. Forbes Winslow, President.

INTUS-SUSCEPTION.

Dr. Coaswell exhibited a portion of the intestine of a boy, two years of age, who had died from intus-susception, on the morning of the 20 th of April; the bowels having been relieved, the child went to school apparently well, but at $n \cdot 0 n$, while returning home, he was seized with vomiting, and presently gave evidence of suffering from severe abdominal pain. Under the use of fomentations and aperients there was no discharge from the bowels, and death took place in about forty-five hours, preceded half an hour by a convulsion. On examination the third day after death, the ileum was distended with flatus, and pale until about four inches from the colon, when it became dark red. Within the colon, cose to the ileo-cæcal valve, a soft solid body was felt about the size of a fowl's egg. This, on being exposed, proved to consist of the terminal portion of ilium, inverted to the extent of about three inches, deeply plicated, and in a h gh state of sanguineous conges ion. An ovoid form was produced by the extremity of the impacted bowel being recurved towards its base, the orifice being thus completely closed by opposition with the superior folds of the mucous membrane. A small quantity of bloody mucus was found in the colon.

\section{LONDON MEDICAL REFORM COMMITTEE}

At a meeting of legally-qualified medical practitioners held on Wednesday, May 18, 1853, it was resolved to form a committee to promote the passing through Parliament of the Medical Reform Bill, prepared by the Provincial Medical and Surgical Association.

The committee invite the earnest and immediate co-operation of all qualified medical men throughout the United Kingdom.

This Bill, promising to obtain for the medical profession uniformity of education, the right of practising throughout the United Kingdom, and registration of all medical men, will, it is hoped, satistactorily to all parties, settle the great question of medical reform.

The committee would urge the necessity of petitions being immediattly sent to Parliament, pressing upon the legislature the importance of passing the Medical Reform Bill this session.

Feritions for signature may he had upon application to the Secretaries, to whom all communications and subscriptions may be forwarded, addressed to 22 , Old Buriington-street, London.

Edwin Lankfster, M.D., Chairman.

J. D. JoNEs, M D. W. II. Torallen,

Secretalies.

Lunatios under Inquisition.-From a return just printed by order of the House of Lords, of the number of lunatics under inquisition, who are resident in asylums, and the amount of their respective incomes and allowances for maintenance, it appears that there are 238 persous confined in asylums, mcluding licensed houses. In many of the cases the whole income is applied for maintenance. The largest income, in one case is $£ 5000$ a-year, of which $£ 700$ is for the support of the lunatic, aud $\$ 2500$ for keeping up Hazlewood Castle. 